Tomasz Abel*

\title{
Laboratory tests and analysis of CIPP epoxy- resin internal liners used in pipelines - part I: comparison of tests and engineering calculations
}

https://doi.org/10.2478/sgem-2021-0002

received November 10, 2020; accepted January 31, 2021.

\begin{abstract}
Tests that were carried out in order to obtain knowledge of the actual values of strength parameters obtained by CIPP liners that are used to repair pipelines. Specimens of liners made of high quality polyester felt cured with epoxy resin were subjected to tests. The scope of the performed studies corresponded with the scope of acceptance tests, which are carried out in the investment process during quality control of renovation works. Specimens of liners taken from sewers with 3 different diameters, i.e. $200 \mathrm{~mm}, 350 \mathrm{~mm}$ and $500 \mathrm{~mm}$ were selected as representative for underground sewage networks. The obtained results enabled the calculations carried out in the course of design work to be verified, and differences between the model values of the strength parameters obtained from the calculations, and real values that are burdened with irregularities resulting from the conditions prevailing at a construction site and which were obtained for specimens taken from their built-in locations to be compared.

The tests confirmed that it is possible to renovate - using CIPP liners - sewers with a lot of structural and material damage that negatively affects a liner's geometry. The implementation of the reinforcing internal coating in a sewer enables its further safe operation. The direct application value of the research involves the enlargement and clarification of knowledge concerning the actual loadbearing capacity of CIPP liners.
\end{abstract}

Keywords: No-dig technologies, laboratory tests, closefit lining, sewer rehabilitation

\footnotetext{
*Corresponding author: Tomasz Abel, Wroclaw University of Science and Technology, Poland, E-mail: tomasz.abel@pwr.edu.pl
}

\section{Introduction}

The underground network infrastructure, which is used to transport sanitary, economic and industrial sewage, operates in very difficult environmental conditions. All pipeline-involved sewage networks are exposed to mechanical factors, including traffic loads, ground loads and ground water pressure, as well as chemical factors such as aggressive chemical compounds contained in sewage and the chemical aggressiveness of groundwater. All of these factors, over many years of network use, result in a lot of damage to pipelines, including:

- surface corrosion (depending on the type of construction material),

- longitudinal cracks in pipes of a local and linear nature - along a considerable length,

- transverse cracks of a local nature,

- damage at the joints of individual pipes that cause leaks,

- cross-sectional deformations resulting from the weakening of the pipe structure caused by cracking, or surface and deep corrosion,

- ground water infiltration,

- waste water exfiltration.

Exemplary damage to sewers is shown in Figure 1, where there is longitudinal fracture and material loss (part a), transverse fracture (part $b$ ), damaged connections and joint movements (part c).

So far, a lot of tests and simulations have been carried out to determine the value of strength parameters depending on the type of damage. Strength parameters of pipes and internal linings are tested for a wide range of materials. One of the similar material is glass fibrereinforced polymer (GFRP) composite, which is used by many industries. The subject of the research and simulations were, for example, damage such as osmotic blisters [1]. Under investigation were also failure analysis of cracked steel pipe repaired by GFRP. To examine the 

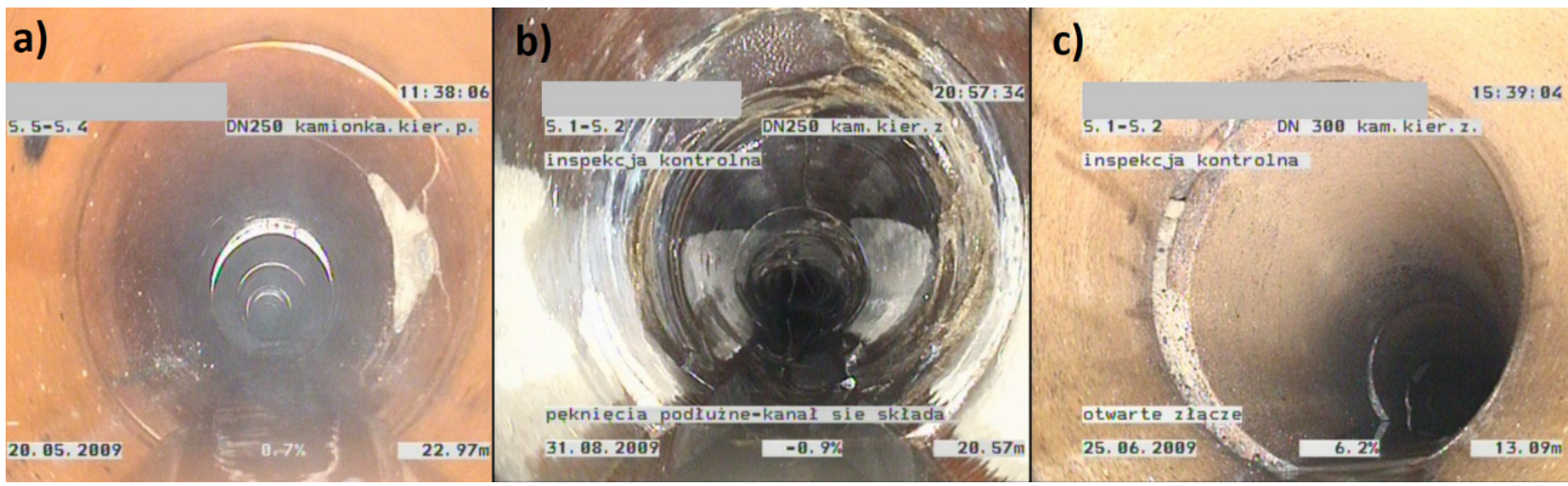

Figure 1: Examples of pipe damage: a), b) cracks and structure defects, c) damaged connectors.

GFRP composite, a patch with different orientations of fibre was used for the finite element method (FEM). The tests were carried out to verify the effect of the fibre orientation on strength [2]. In another case, the studies concerned progressive failure of pinned joint in quasiisotropic GFRP composite laminates used in pipeline. Control simulations were performed using a threedimensional (3D) finite element model [3].

The technical condition of sewage pipes has been the subject of analyses carried out as part of many scientific works for years [4]. As a result of many years of research and assessments of the technical condition of underground networks, the classification of pipelines with regard to the scope and type of damage occurring in them has been adopted. This classification, which was indicated in the ATV 143-2 guidelines [5] and created for the purposes of selecting the appropriate technique of a sewer's repair in the design phase, divides pipelines into four technical conditions (see Fig. 2 [5]):

- Technical condition I - The existing conduit maintains its load capacity. There is only minor damage in the form of, for example, leaking joints or hairline scratches.

- Technical condition II - The existing conduitsoil system maintains its ability to transfer loads. The permissible damage for this state includes longitudinal scratches with small deformations of the cross-section $\delta \mathrm{v}<6 \%$.

- Technical condition III - The existing conduit-soil system has lost its ability to carry loads independently; there are clear deformations of the cross-section $\delta \mathrm{v} \geq$ $6 \%$.

- Technical condition IIIa - The existing conduit-soil system has lost its ability to carry loads independently. There are clear deformations of the cross-section $\delta \mathrm{v}$
$>6 \%$, structural damage to the parent pipe, as well as soil losses in the pipeline surroundings - it is an emergency condition that can result in failure.

In the case of gravitational sewer pipelines, it is only their cross-section that is considered in the calculations. This is due to the fact that the static scheme is adopted for the longitudinal profile of gravitational networks, that is, the articulated nature of connections of individual pipe elements and the character of the course of bending moment values resulting from it. The correct classification of the technical state of a pipeline is necessary for the appropriate performed repair, which is highlighted in many scientific papers [6, 7].

Underground networks, located in urban areas, are most often renovated with the use of trenchless technologies, which enable work in compact urban conditions to becarried out without the need for earthworks that are burdensome for residents. In addition, the use of such technologies significantly limits the difficulties connected to the functioning of the urban agglomeration. Equally important with regard to the economic and logistic aspect is that trenchless technologies also have a relatively short renovation time $[8,9]$.

Trenchless pipeline repair technologies that have been most frequently used for many years are solutions based on the implementation of a liner inside the existing conduit, which forms a composite structure with the existing pipeline. These liners are a group of the so-called CIPP liners - cured-in-place pipe - which include a wide range of material solutions. CIPP liners are made of felt non-woven polyester or a fibreglass mat. These materials are saturated with synthetic resins [10]. 
a) technical condition I

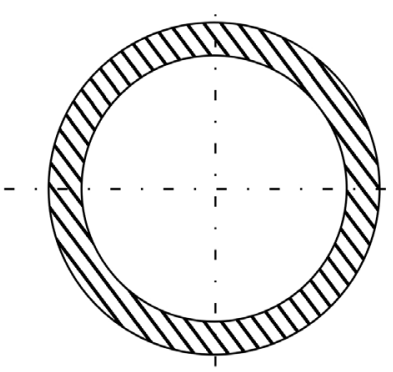

b) technical condition II

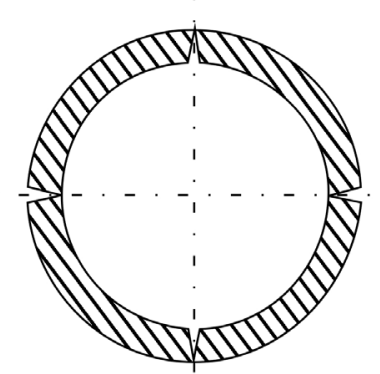

c) technical condition III

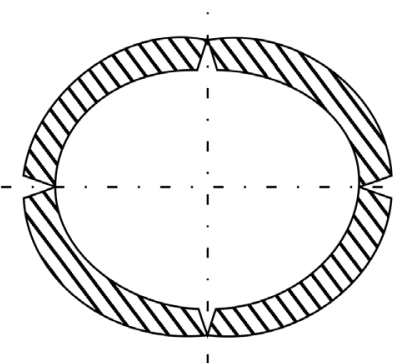

d) technical condition IIIa

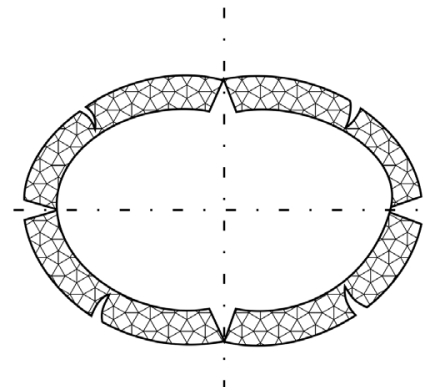

Figure 2: Technical conditions according to ATV 143-2; a) technical condition I; b) technical condition II; c) technical condition III; d) technical condition III a [5].

\section{Research methods}

Guidelines for the design and implementation of sewer repairs using CIPP liners are included in a series of European standards. The most important information is provided in:

- PN-EN ISO 11295: 2018-02 - Classification and information on the design and applications of plastic piping systems used for renovation and replacement [11].

- PN-EN ISO 11296-1: 2018-04 - Plastic piping systems for the renovation of underground non-pressure drainage and sewerage networks - Part 1: General provisions [12].

- PN-EN ISO 11296-1: 2018-04 - Plastic piping systems for the renovation of underground non-pressure drainage and sewerage networks - Part 4: Lining with cured-in-place pipes [13].

- PN-EN ISO 11297-1: 2018-05 - Plastic piping systems for the renovation of underground drainage and sewerage networks under pressure - Part 1: General provisions [14].

- PN-EN ISO 11297-4: 2018-03 - Plastic piping systems for the renovation of underground drainage and sewerage networks under pressure - Part 4: Lining with cured-in-place pipes [15].

All of the aforementioned standards refer to the various worldwide-used systems of thermosetting resins, compatible fibre carriers and other plastic components from which CIPP liners are made of.

Depending on the technical condition of a conduit, which was assessed at the stage preceding the design process, that is, during diagnostic tests, the required strength and material parameters of the liner are determined. These parameters constitute guidelines for the selection of an appropriate technical solution. The adopted assumptions regarding the material to be used and its strength characteristics are verified in the design process based on static and strength calculations. Finally, the quality of the material that was used inside a conduit during renovation, which is understood as compliance with the parameters specified in the design, is assessed by performing appropriate laboratory tests of specimens taken from the liner that was used for repair. [16]

As a part of acceptance tests, which are conducted in accordance with PN-EN ISO 14125: 2001 - Fibrereinforced plastic composites - Determination of flexural properties [17], and also PN-EN ISO 178: 2019-06 - Plastics - Determination of flexural properties [18], the following laboratory tests are carried out:

- Bending tensile strength - This is a characteristic feature for liners and allows the permissible load value to be determined. The value of this strength is defined by the point of destruction of the sample that is subjected to an increasing load. If the bending tensile strength turns out to be too low, the test sample may be damaged before reaching the permissible deformation limit. During the three-point bending test, the load is increased until the first decrease in strength of the tested sample (short-term test). This point indicates the beginning of the cracking of the liner.

- Modulus of longitudinal elasticity - The test method also involves the three-point bending test, which is carried out on the basis of PN-EN ISO 178: 2019-06 as a short-term test. This test is considered passed when the parameters of the tested liner sample reach at least the expected value. This value corresponds to the data declared by the producer or supplier, which was obtained in the course of qualitative tests conducted during the production of the material. 
The third criterion, which is important for the assessment of the permissible load of the tested liner, is its wall thickness. As mentioned above, in the design process, certain assumptions are made in the static calculations, which must then be met during the installation phase of the liner, that is, ensuring its required minimum thickness. The fitted liner is measured using a precise calliper in six places. During the measurements, the inner or outer foil and the excess of the resin layer are not taken into account [19].

The last, but no less important test criterion, is the waterproofness of the liner. One of the common research methods uses the phenomenon of underpressure, which, in the case of the lack of tightness, causes the penetration of liquid particles through the structure of the material. During the test, depending on the type of liner, the outer foil is first removed from the sample, and then, the inner foil is cut according to a set pattern. Afterwards, water with dye is poured on the inside part of the liner, and 0.5 bar pressure is applied to the outside. The liner is considered as leaky if drops, foam or moisture begin to form on the outside of it during the test.

The second test method that can be carried out to verify water permeation is the GWT (Germann Water Permeation Test), which enables on-site testing directly on a material (sample). In the GWT, a sealed pressure chamber is attached to the tested surface and then filled with boiled coloured water, which is subjected to forced pressure - for CIPP liners with a value of min. 0.5 bar. No water leakage is a prerequisite for a positive test result [19].

\section{Experimental works}

\subsection{Introduction}

With the widespread use of trenchless technologies around the world, it has become necessary to conduct research to expand knowledge concerning both the strength parameters of used CIPP liners and also the benefits of strengthening existing pipelines and ensuring their continued safe operation.

Ian. D. Moore [20] in the years 2003-2005 conducted a series of tests on models of pipes that were reinforced using CIPP liners. The scope of their tests included strength tests and pressure tests of a cast iron pipe with an internal close-fit repair liner. In addition, numerical analyses using the FEM were carried out as part of the research work. The conducted numerical calculations were of a control nature. The research resulted in the confirmation of the correctness of the assumptions that were adopted at the stage of designing the pressure pipeline repair and also in the obtaining of knowledge concerning the strength parameters of this type of composite structure after several years of its use.

In 2011, R. Sterling from the Trenchless Technology Centre in Louisiana conducted a study of CIPP liners that were installed in a conduit [7]. The liners were tested after 30 years of pipeline operation. The purpose of the tests was to check the strength parameters of a liner and compare them with the designed strength parameters that were declared by the manufacturer. The scope of the research also included a visual inspection of the liner. The following parameters were tested: hardness of the liner, its ovalisation and wall thickness. The most important tests that were carried out included the three-point bending test based on ASTM D790 [21], the tensile test based on ASTM D638 [22] and a series of buckling tests carried out on a natural scale model.

In turn, in 2014, R. Sterling [23] implemented another research programme concerning CIPP liners. The samples of liners were taken from renovated sewers from two different cities, that is, Denver and Columbus in the USA, and then tested. The scope of research was very wide and included the measurement of the following parameters: thickness, annular gap, ovality, density, specific gravity, porosity, flexural strength, flexural modulus, tensile strength tensile, modulus, surface hardness, glass transition temperature and spectroscopy.

In the period between 2008 and 2011, T. Abel carried out a research programme, the effects of which were published in 2015 in [24]. Tests were conducted on pipes that were reinforced with a close-fit liner of the Trolining type (also belonging to the CIPP group) and the liner itself. This research resulted in the obtaining of knowledge concerning the actual increase in the loadbearing capacity of the sewer with regard to the strength parameters of the liner. The added value of the conducted tests was the determination of the actual value of the ring stiffness for circular cross-sections and also the bending strength for egg-shaped cross-sections.

One of the leading scientists in Poland who deals with issues related to trenchless technology is A. Kuliczkowski from the Kielce University of Technology. He studies the issues related to the application of close-fit liners of the CIPP type. One of his papers [25] describes the results of tests that were carried out on pipes reinforced with CIPP liners and also on the samples of these liners. As part of the research programme, samples of concrete, stoneware and PVC pipes with resin coatings of various thicknesses installed inside them were tested. The results obtained 


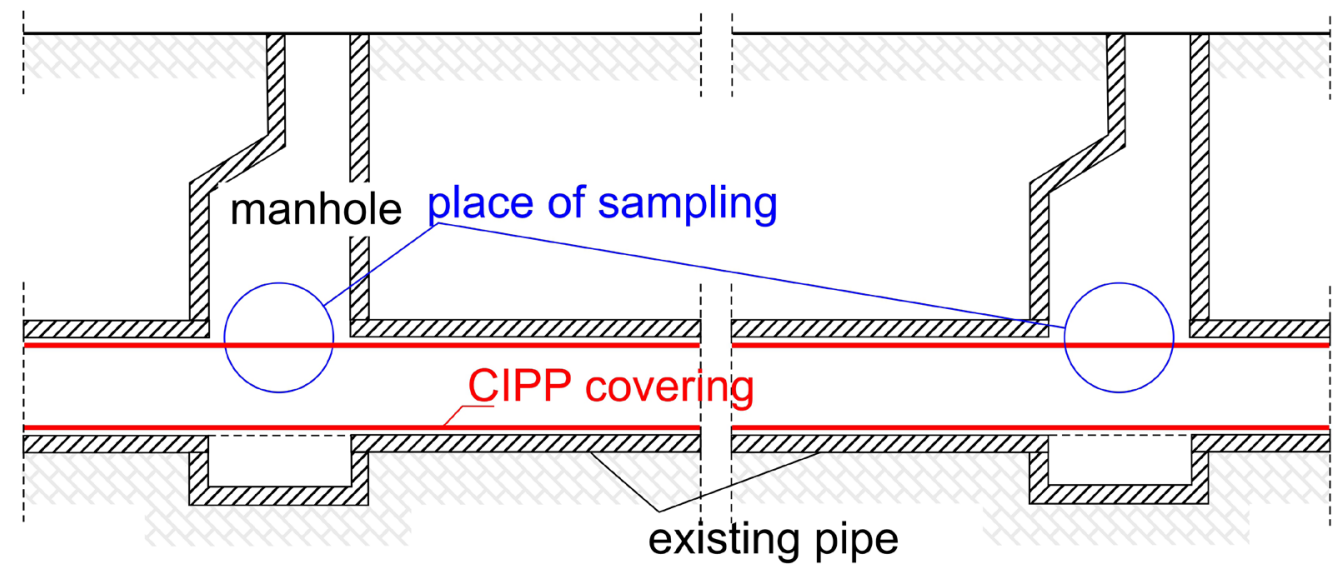

Figure 3: An overview sketch of the liner's installation.

in the course of the research confirmed the legitimacy of taking into account a complex system in the calculations, that is, assuming the cooperation of an existing pipe with an internal coating. This is extremely important because of the economic effects and also structural and material properties.

Regardless of the widely conducted strength tests of CIPP liners and conduits reinforced with them, the impact of the liner, as a building material, on the natural environment cannot be omitted. Issues related to the emission of hazardous substances into the environment during the installation of CIPP liners and their subsequent operation have been raised by, among others, K. Ra., S.M. Teimouri Sendesi et.al. A scientific paper, published in 2019 in the Journal of Hazardous Materials [26], presented the issue of the emission of chemical compounds during the installation of CIPP liners. The following chemical compounds were identified during the research: styrene, methylene chloride and phenol. These studies showed that it is necessary to conduct control over the concentration of hazardous substances to prevent the exceeding of their permissible values.

As part of the research carried out by the T. Abel [24, 27], a series of tests of CIPP liner samples was conducted. The samples were taken by the contractor of the sewer renovation works from the place of the liner's installation (see Fig. 3). The research programme that is described in this article was carried out to gain knowledge about the differences between the actual strength parameters of liners installed in sewers and the values assumed in the documentation at the design stage. Samples of a liner taken from its built-in location may be affected by irregularities, such as: variable wall thickness, ovalisation resulting from conduit deformation, corrugation of the liner's surface and other local disorders that affect the heterogeneity of the repair coating. Therefore, it is very important to carry out tests on as many samples as possible. This enables results close to the average value that is guaranteed by the coating to be obtained.

The assessed CIPP liner is made of high-quality polyester felt that is covered with a layer of polypropylene. An epoxy resin, with a composition ensuring its safe operation and no negative impact on the environment (which was confirmed by the relevant manufacturer's certificates), was used as the curing material for the liner. Fragments of the liner were cut from the places where it passes through the inspection wells to prepare laboratory samples (see Fig. 3). Standard [13] recommends that the sample should be taken in an intermediate well, in the place where the liner matches the shape of the conduit being repaired.

Fragments of liners taken from conduits with diameters of $\varnothing 200, \varnothing 350$ and $\varnothing 500$, representative for nonman-entry sanitary sewage networks that occur in urban areas, were tested.

The WDW-100-type machine was used to perform strength tests [28]. This machine is widely used for mechanical testing of the tensile, compressive, bending, shear and tearing strength of non-metallic materials such as rubber, plastics, textiles, electric wires, cables, composite materials, leather, nonwovens, plastic fabrics, geotextiles and sheets of paper, etc., as well as metallic materials such as metal wires, metal foils, metal sheets, metal rods, etc.

The thicknesses of the tested samples were measured in accordance with PN-EN ISO 3126: 2006 Plastic pipe 


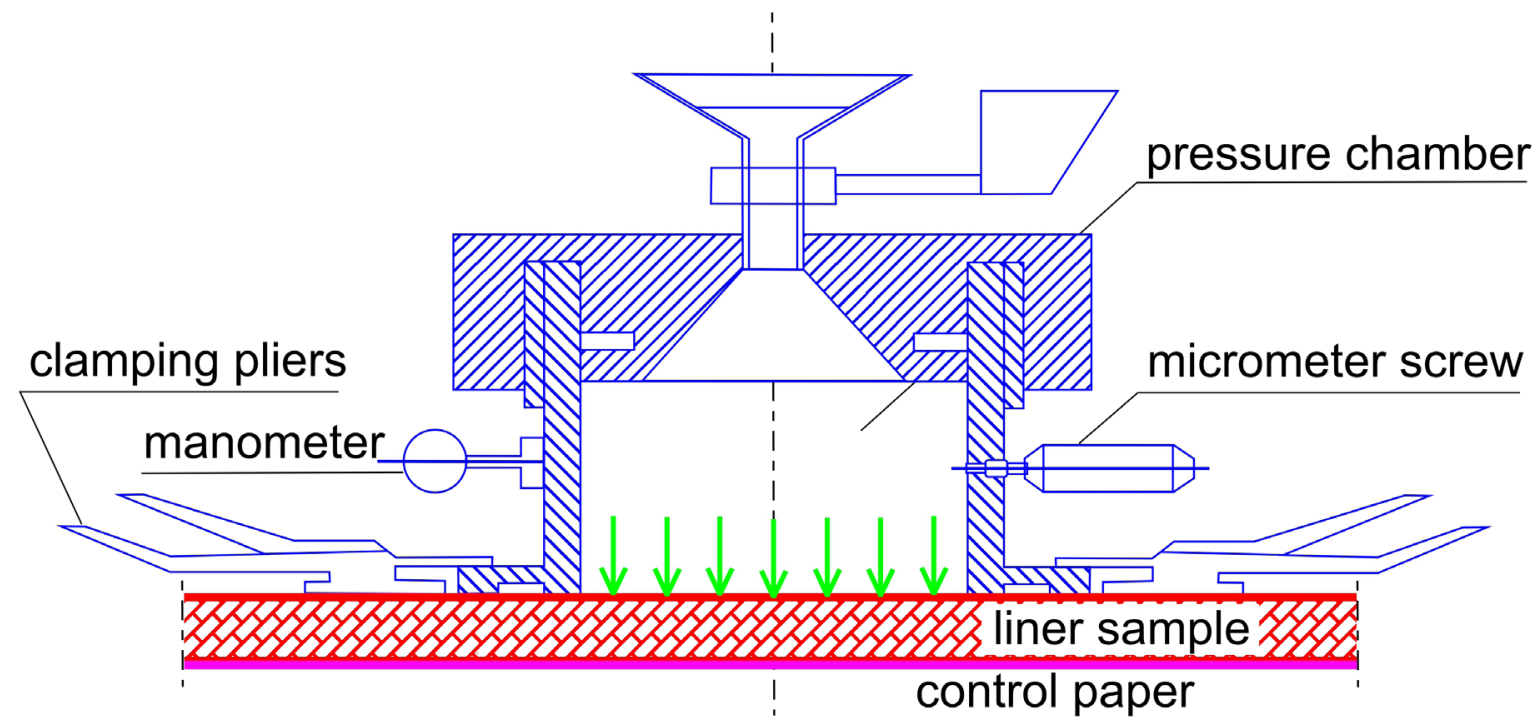

Figure 4: Illustration of the GWT method for measuring water permeability [30].

systems - Plastic components - Checking dimensions [29] while applying the following conditions and measurement parameters:

- The tests were carried out at room temperature $\left(23^{\circ} \mathrm{C}\right.$ $\pm 2^{\circ} \mathrm{C}$ ),

- Measurement accuracy: $\pm 0.01 \mathrm{~mm}$,

- A test result is an average of at least 24 thickness measurements that were taken in different places on each of the provided samples.

Water permeation tests were performed using the GWT method [30]. This test involves a sample surface being subjected to the forced action of the assumed pressure of water, which fills a specially constructed pressure chamber. The test scheme is shown in Figure 4 [30]. These tests are intended to check whether the installed CIPP liner will retain full water penetration tightness after abrasion.

According to guidelines [5], the following boundary conditions for performing tests apply to flexible sleeves:

- The tests were carried out at room temperature $\left(23^{\circ} \mathrm{C}\right.$ $\pm 2^{\circ} \mathrm{C}$ ),

- A mesh made of 10 mutually perpendicular $2 \mathrm{~mm}$ deep incisions at a distance of $4 \mathrm{~mm}$ apart was made on each sample.

Research procedure:

- Tested surface $-3,018 \mathrm{~mm}^{2}$,

- The test fluid is implemented on the internal side of a sample,
- $\quad$ Test pressure -0.5 bar \pm 0.025 bar,

- 30 minutes trial time,

- Test medium - drinking water, coloured.

The condition confirming the positive result of the test is the absence of water leaks. Water leakage occurs when the control layer (in this case paper), which is laid on the sample on its outside, is discoloured by moisture. However, discoloration of the laminate is allowed.

During the three-point bending test (Fig. 5), the values of the applied force and the deformation obtained at a given moment were read in accordance with the graph below (see Fig. 6 [18]):

Individual characteristics were calculated using the relationships between flexural stress:

$$
\sigma_{f}=\frac{3 * F * L}{2 * b * h^{2}}
$$

Where: $\sigma_{\mathrm{f}}$ - flexural-stress parameter [MPa], F - applied force $[\mathrm{N}], \mathrm{L}-\operatorname{span}[\mathrm{mm}], \mathrm{b}$ - width [mm], $\mathrm{h}$ - thickness of the specimen $[\mathrm{mm}]$

and flexural strain:

$$
\varepsilon_{f}=\frac{6 * S * h}{L^{2}}
$$

Where: $\varepsilon_{\mathrm{f}}$ - flexural strain [-][\%], $\mathrm{s}$ - deflection $[\mathrm{mm}], \mathrm{h}-$ thickness [mm], L - span [mm] 


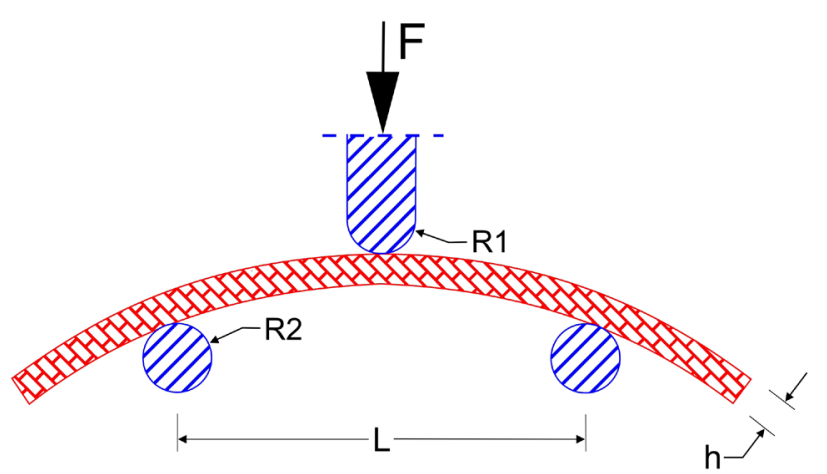

Figure 5: Three-point bending - test scheme.

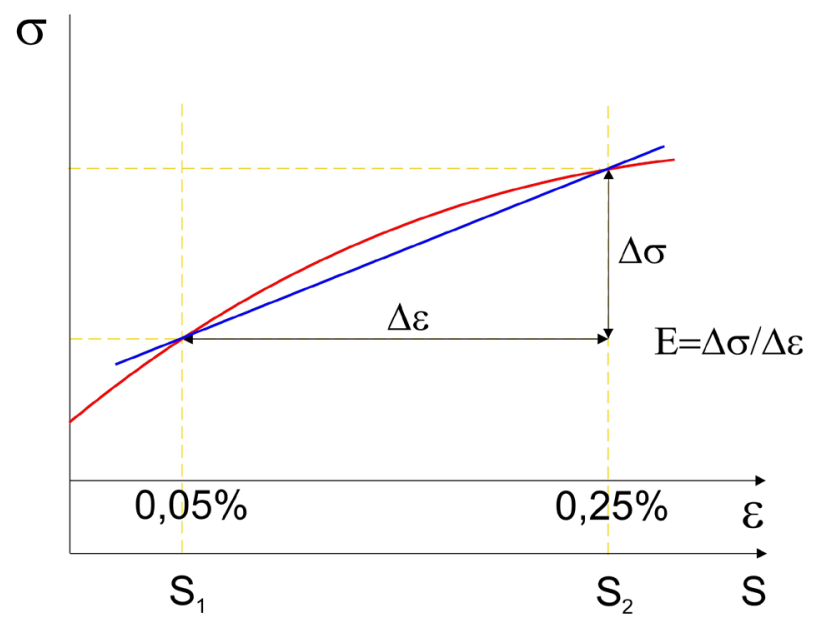

Figure 6: Accuracy requirements for the determination of the flexural modulus [18].

Values calculated during the tests are flexural modulus $\mathrm{s}_{\mathrm{i}}$, whose value is calculated for two load phases (see Fig. 6) and, being the final result, deflection $\mathrm{E}_{\mathrm{f}}$ :

$$
S_{i}=\frac{\varepsilon_{f i} * L^{2}}{6 * h}
$$

( $\mathrm{i}=1$ or 2 , see fig. 6 )

Where: $\varepsilon_{\mathrm{fi}}-$ corresponding flexural strain [-][\%], $\mathrm{s}_{\mathrm{i}}$ - one of the deflections [mm], $\mathrm{h}$ - thickness [mm], $\mathrm{L}$ - span [mm]

$$
E_{f}=\frac{\sigma_{f 2}-\sigma_{f 1}}{\varepsilon_{f 2}-\varepsilon_{f 1}}
$$

Where: $\sigma_{\mathrm{f} 1}-$ flexural-stress parameter, measured at deflection $s_{1}[\mathrm{MPa}], \sigma_{\mathrm{f} 2}$ - flexural-stress parameter, measured at deflection $\mathrm{s}_{2}[\mathrm{MPa}]$

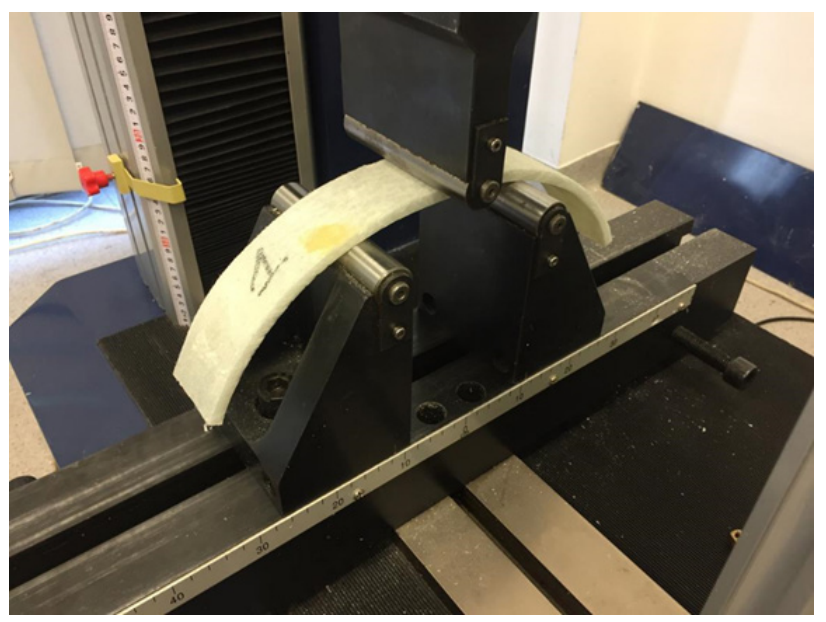

Figure 7: Laboratory test of a liner - diameter $200 \mathrm{~mm}$.

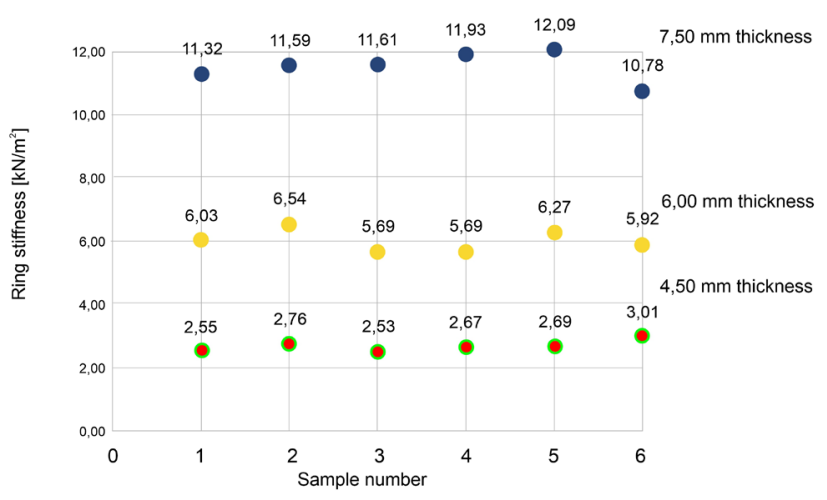

Figure 8: Ring stiffness for 200 mm diameter samples.

Finally, we can calculate the value of the ring stiffness $\mathrm{S}_{\mathrm{N}}$, which is the most important parameter in terms of the durability of the lining:

$$
S_{N}=\frac{E_{f} * h^{3}}{12 * d_{m}^{3}}
$$

where: $E_{f}$ - elastic modulus of a material, [MPa], $\mathrm{h}$ sample thickness $[\mathrm{mm}], \mathrm{d}_{\mathrm{m}}$ - average sleeve diameter, $[\mathrm{mm}]$.

\subsection{Samples in diameter $200 \mathrm{~mm}$}

The first tests involved the samples of a liner that were taken from conduits with an internal diameter of $200 \mathrm{~mm}$. In these sewers, depending on their technical condition [5], liners with the following thicknesses, that is, 4.5, 6.0 and $7.5 \mathrm{~mm}$, and a declared modulus of elasticity of 2,500 MPa were installed. From each liner with a certain 


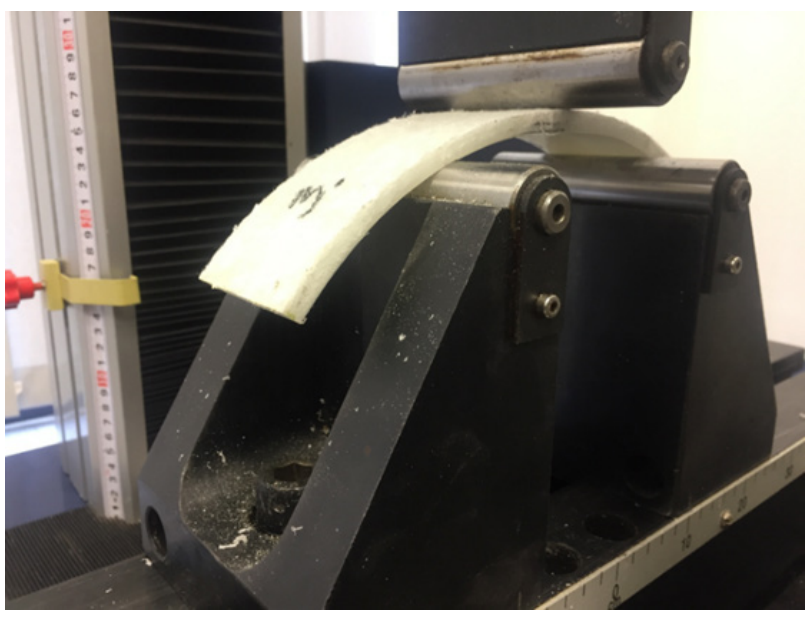

Figure 9: Laboratory test of a liner - diameter $350 \mathrm{~mm}$.

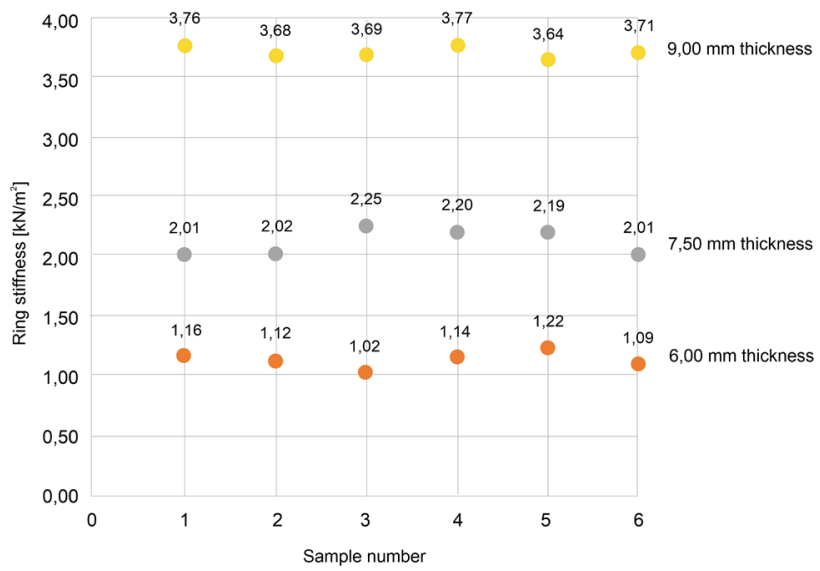

Figure 10: Ring stiffness for $350 \mathrm{~mm}$ diameter samples.

thickness, 6 samples were taken from different places of the liner's installation for testing. The test stand with sample in diameter $200 \mathrm{~mm}$ is shown in Figure 7:

Tests of the liner samples taken from the DN $200 \mathrm{~mm}$ conduit confirmed the average elastic modulus declared by the manufacturer at a level of 2,524.50 MPa. In the case of a conduit with a diameter of $200 \mathrm{~mm}$, the assessed liner is obtained, depending on the wall thickness. The obtained values of ring stiffness are shown on a collective graph (see Fig. 8):

\subsection{Samples in diameter $350 \mathrm{~mm}$}

The next tested liner samples were taken from ducts with an internal diameter of $350 \mathrm{~mm}$, in which, depending on their technical condition [5], liners with the declared modulus of elasticity of 2,500 $\mathrm{MPa}$, and the following

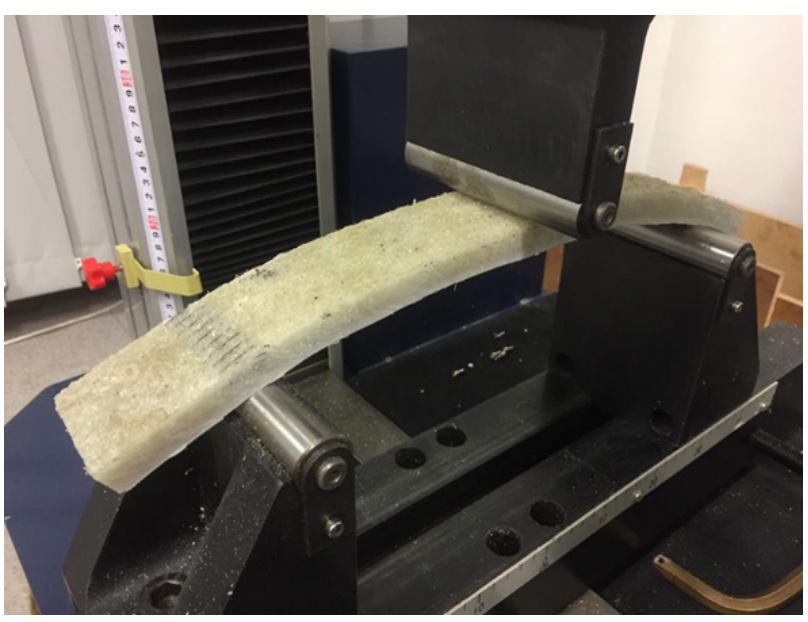

Figure 11: Laboratory test of a liner - diameter $500 \mathrm{~mm}$.

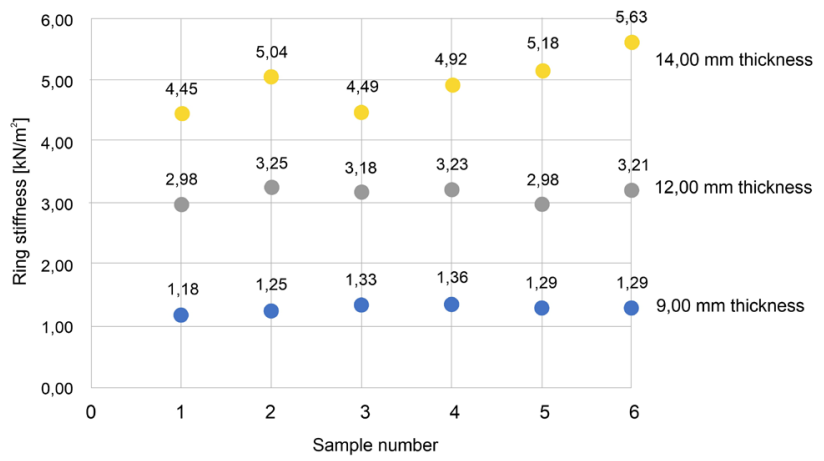

Figure 12: Ring stiffness for $500 \mathrm{~mm}$ diameter samples.

thicknesses declared by the manufacturer, that is, 6.0, 7.5 and $9.0 \mathrm{~mm}$, were installed. From each liner with a certain thickness, 6 samples were taken from different places of the liner's installation for testing. The test stand with sample in diameter $300 \mathrm{~mm}$ is shown in Figure 9:

Tests of the liner samples taken from the DN $350 \mathrm{~mm}$ conduit confirmed the average elastic modulus declared by the manufacturer at a level of 2,515.23 $\mathrm{MPa}$. In the case of a conduit diameter of $350 \mathrm{~mm}$, the assessed liner is obtained, depending on the wall thickness. The obtained values of ring stiffness are summarised on a collective graph (see Fig. 10):

\subsection{Samples in diameter $500 \mathrm{~mm}$}

The last tested liner samples were taken from conduits with an internal diameter of $500 \mathrm{~mm}$, in which, depending on their technical condition [3], liners with the declared modulus of elasticity of 2,500 $\mathrm{MPa}$, and the following 


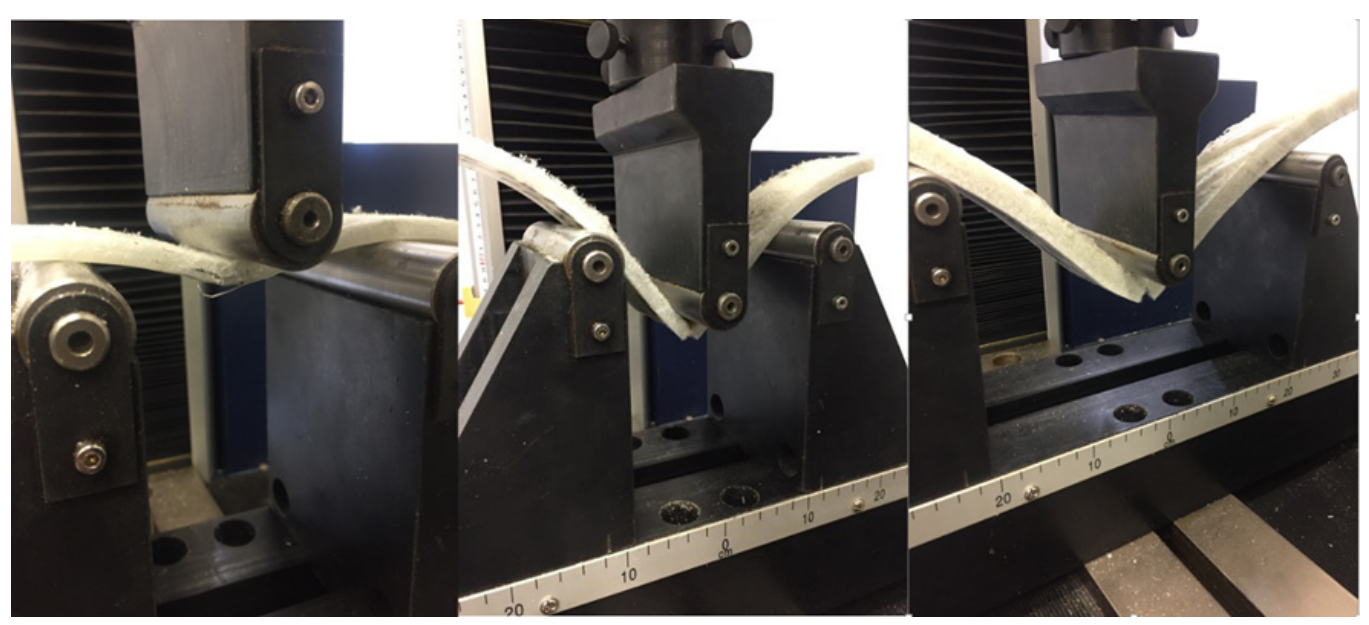

Figure 13: The mechanism of the sample's destruction.

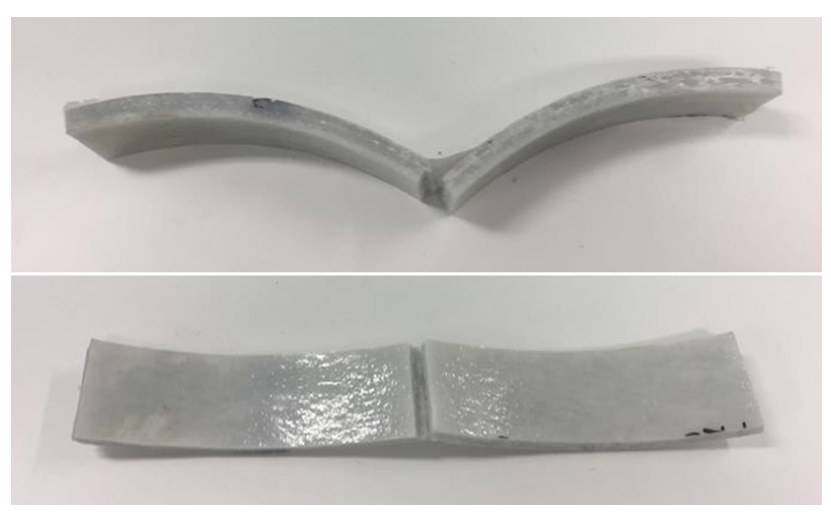

Figure 14: Example of a damaged sample.

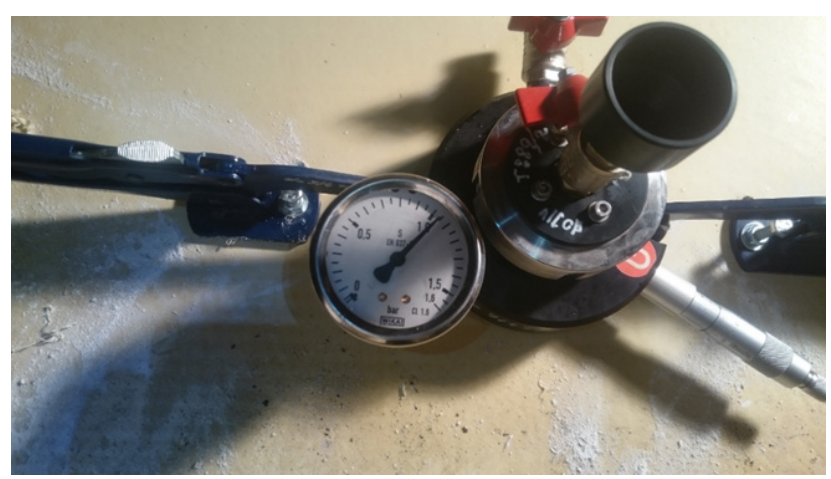

Figure 15: Sample test using the GWT device.

thicknesses declared by the manufacturer, that is, 9.0, 12.0 and $14.0 \mathrm{~mm}$, were installed. From each liner with a certain thickness, 6 samples were taken from different places of the liner's installation for testing. The test stand with sample in diameter $500 \mathrm{~mm}$ is shown in Figure 11:
Tests of the liner samples taken from the DN $500 \mathrm{~mm}$ conduit confirmed the average elastic modulus declared by the manufacturer at a level of 2,549.10 MPa. In the case of a conduit diameter of $500 \mathrm{~mm}$, the assessed liner is obtained, depending on the wall thickness. The obtained values of ring stiffness are summarised on a collective graph (see Fig. 12):

All the tested samples were destroyed in the final phase of deflection - cracking was observed on the stretched side of the tested material. Damage occurred in the phase of the increase of applied concentrated force. Exemplary photos of the mechanism of destruction of the liners samples are presented below - see Figures 13 and 14:

Positive permeability results were obtained for all the tested liner samples. Each of the tested samples turned out to be tight. There was no change in pressure in the chamber of the device, nor discoloration from the outside of the liner or the control layer. An exemplary test is shown in Figure 15:

\section{Engineering calculations}

A calculation algorithm that is commonly used in the design process is the method proposed in guidelines [5]. The theoretical basis for the content of these guidelines is the Glock theory from 1977 [31], which assumed a perfectly circular shape and rigid nature of the host pipe, and also a flexible liner that is perfectly matched to the internal surface.

These guidelines divide the sewers into 4 technical conditions, as indicated in point 2 . For sewers in the 
second technical condition (according to [5]), for which CIPP liners are dedicated, it is assumed that there is a cooperation between an existing structure and an internal reinforcing liner, and that during the dimensioning process, only the hydrostatic pressure of groundwater is considered as a loading acting on a liner.

The calculation procedure is based on checking the following stability condition for the inner liner:

$$
\frac{p_{a, d}}{\text { krit } p_{a, d}} \leq 1,00
$$

where the values of the critical limit pressure are expressed by formula:

$$
\text { krit } p_{a, d}=k_{v, s} * \alpha_{D} * S_{L, d}
$$

and the actual hydrostatic pressure is equal to:

$$
p_{a, d}=p_{a} * 1,5
$$

where:

$$
\begin{gathered}
k_{v, S}=k_{v} * k_{G R, v} * k_{S} \\
\alpha_{D}=2,62 *\left(\frac{r_{L}}{t_{L}}\right)^{0,8}
\end{gathered}
$$

$r_{L}-$ liner radius $[\mathrm{mm}], t_{L}-$ the wall thickness of a liner [mm]

By introducing three types of imperfections in the form of local initial deformation $\omega_{v}$, annular gap $\omega_{s}$ and ovalisation $\omega_{G R, v}$, the adopted calculation scheme is modified, which makes it more similar to the real model that is damaged.

In computational practice, this leads to the use of the following correction factors, which, among others, reduce the critical computational values of the loads that may affect the structure: $\mathrm{k}_{\mathrm{v}}$ - correction factor, which depends on the value of the initial deformation, $\mathrm{k}_{\mathrm{GR}, \mathrm{v}}$ - correction factor, which depends on the value of ovalisation, $\mathrm{k}_{\mathrm{s}}$ - correction factor, which depends on the value of the annular gap.

In the presented case, the following imperfection values were used for the calculations: local initial deformation $\omega_{\mathrm{v}}$ at a level of $3 \%$, annular gap $\omega_{\mathrm{s}}$ equal to $1 \%$ and ovalisation $\omega_{\text {GR,V }}$ equal to $6 \%$. The author's many years of practice in the field of assessing the technical condition of pipelines indicates that the adopted values are characteristic for sewers that have been operated for many years, and that are currently in technical condition II. This enables the use of CIPP liners.

In lowland areas, most sanitary sewers are located at a depth ranging between 1.5 and $3.5 \mathrm{~m}$ below ground level. When assuming the maximum theoretical value of water pressure equal to $3.5 \mathrm{~m}$ in the formula for critical pressure, the stability condition will be met for all the liners subjected to laboratory tests - see Table 1.

The obtained stability condition values show that each of the used liners, with a correctly performed assessment of the technical condition of the existing sewer (classifying it as a system maintaining load-bearing capacity, i.e. in technical condition II, see point 2), provides high safety reserves. The values of the obtained safety factors are shown in Table 2.

\section{Results and discussion}

The tests of CIPP liners used in sanitary sewers, conducted as part of scientific work and cooperation with a company performing underground pipeline repairs, confirmed the strength parameters declared by the manufacturers of the liners. The research showed that CIPP liners made of technical fabric soaked in epoxy resin allow conduits to be repaired and also provide appropriate strength parameters to a structure. In the case of conduits with small diameters, sufficiently high values of liner stiffness are obtained even in the case of small liner thicknesses. In addition, it should be pointed out that the liner thicknesses that are commonly used in practice ensure the obtaining of large reserves with regard to load-bearing safety. Moreover, their safety factor, depending on the level of the conduit's foundation, obtains values within the range of 1.82 up to 11.01.

As a result of the implemented research programme, it is possible to state that for liners made of technical fabric impregnated with epoxy resin, slightly higher strength parameters are obtained from the calculations based on the algorithm proposed in [5] when compared to the parameters obtained from testing the samples of liners taken from the place of their installation. The conducted tests show that ring stiffness, in extreme cases, reaches values lower by about $16 \%$ when compared to the values adopted in the calculations - see Tables 3, 4 and 5. Despite this, and thanks to the safety factors used in the calculations, the load capacity criterion is still met. Large reserves of load-bearing capacity of the liners are obtained. They are desirable due to the expected 


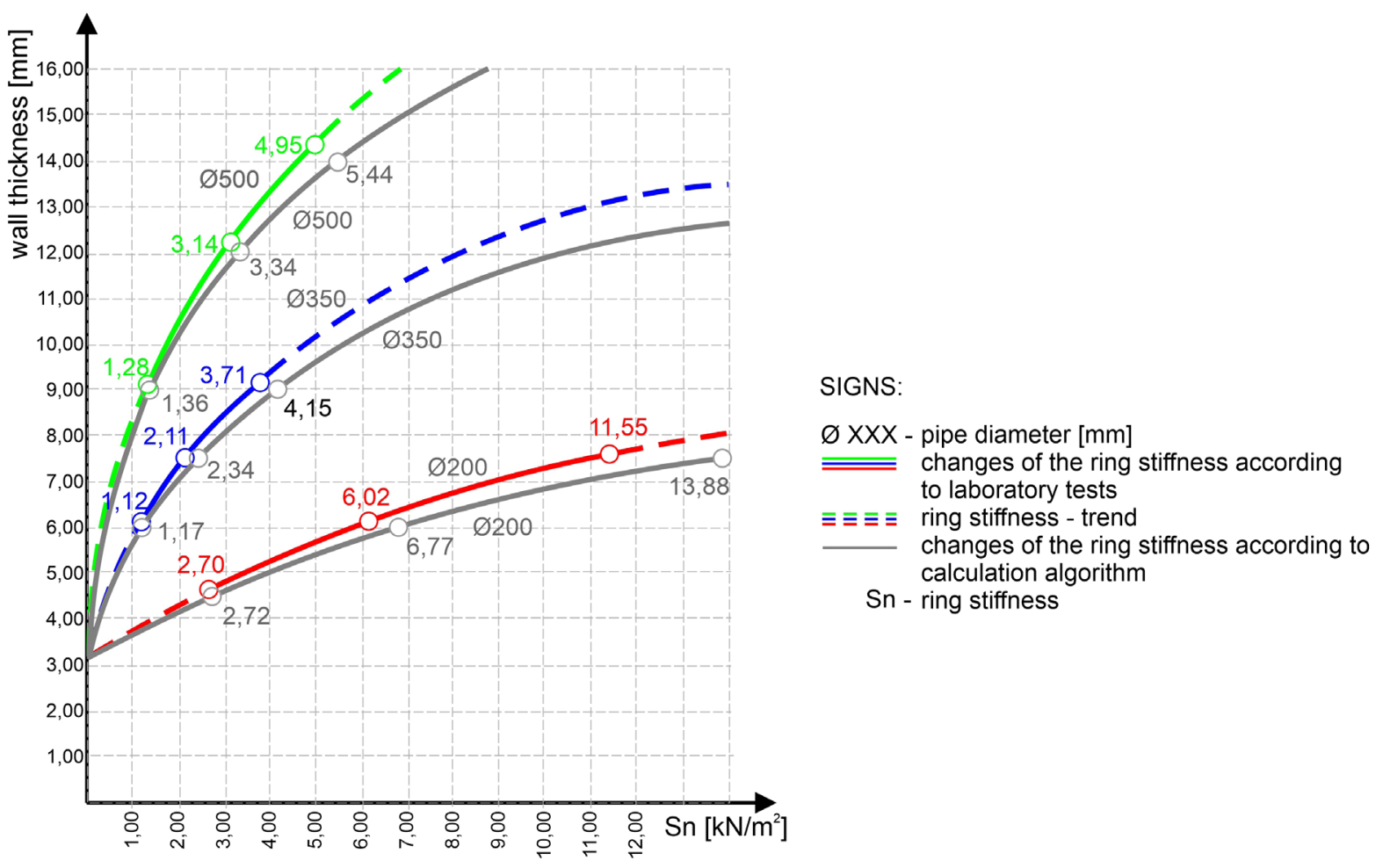

Figure 16: Real and computational ring stiffness for different diameters

period of trouble-free operation of a reinforced conduit, which should be equal to 50 years. Due to the fact that sewer networks operate in very complex and difficult environmental conditions (mechanical and chemical loads), it seems necessary to improve strength parameters while maintaining sufficiently high safety factors. This, as demonstrated in the course of scientific work, is ensured by the use of CIPP liners.

\section{Conclusions}

The calculation algorithm that is used in the designing process is correct with regard to the selection of material parameters, which was demonstrated by comparing the calculations made based on guidelines [5] with the values obtained in the course of laboratory tests. This is shown in Figure 16:

As can be seen from the conducted tests and calculations, for conduits in technical condition II [5], it is sufficient to provide ring stiffness of a liner at the level of $2.0 \mathrm{kN} / \mathrm{m}^{2}$. This, when assuming the cooperation of an existing conduit with a reinforcing liner, guarantees further safe operation of the network and eliminates the progression of factors that cause deterioration of the technical condition of the conduit.

In addition, the conducted permeability tests confirmed the lack of migration of hazardous substances (aggressive chemical compounds contained in sewage). This significantly affects the slowing down of the chemical corrosion process of the material from which the renovated conduits are made. An additional aspect involves the elimination of groundwater infiltration into a conduit, and the filtration of wastewater into the ground.

To sum up, the application of the above-described research and calculation procedures guarantees the desired effect, that is, the internal CIPP reinforcement lining with parameters that guarantee a long period of failure-free exploitation of the pipeline.

\section{References}

[1] Abd-Elhady A.A., Meroufel A., El-Din M Sallam H., Atta M., 2020. Experimental and numerical determination of critical osmotic blister size affecting the strength of aged FRP seawater pipe, Polymers and Polymer Composites, First Published, May 8. 
[2] Elhady A., El-Din H., Sallam M., Malik R.A., 2020. Investigation of fatigue crack propagation in steel pipeline repaired by glass fiber reinforced polymer, Composite Structures, Vol. 242, 112189.

[3] Abd-Elhady A.A., Mubaraki M.A., M Sallam H.E., 2018. Progressive failure prediction of pinned joint in quasi-isotropic laminates used in pipelines, Lat. Am. Journal of Solid and Structures Vol. 15(6).

[4] Madryas C., Przybyła B., Wysocki L., 2010. Research and Evaluate the Technical Condition of Sewer Pipes. Dolnoslaskie Educational Publisher, Wroclaw.

[5] DWA-A 143-2: Sanierung von Entwässerungssystemen außerhalb von Gebäuden Teil 2: Statische Berechnung zur Sanierung von Abwasserleitungen und -kanälen mit Lining und Montageverfahren, Lipiec 2015

[6] Matthews J. C., Selvakumar A., Condit W., 2012. Demonstration and evaluation of an innovative water main rehabilitation technology: Cured-in-Place Pipe (CIPP) lining, Water Practice \& Technology Vol 7 No 2, IWA Publishing.

[7] Allouche E., Alam S., Sterling R., Condit W., Selvakumar A., 2011. Forensic investigation of a generation old cipp liners, North American Society for Trenchless Technology (NASTT), Paper D-5-04, No-Dig Show 2011, Washington

[8] Kuliczkowski A., 2010. Trenchless technologies in environmental engineering, Wydawnictwo Seidel-Przywecki Sp. z o.o.

[9] Kolonko A., Kujawski W., Przybyła B., Roszkowski A., Rybarski S., 2011. Basics of trenchless technical rehabilitation of water and sewage pipelines in urban areas, Izba Gospodarcza „Wodociągi Polskie”, Bydgoszcz.

[10] Madryas C., Kolonko A., 2010. Comments on CIPP liners, Inżynieria Bezwykopowa September - October 5, 2010 [35], Krakow.

[11] PN-EN ISO 11295:2018-02 - Classification and information on design and applications of plastics piping systems used for renovation and replacement

[12] PN-EN ISO 11296-1:2018-04 - Plastic piping systems for the renovation of underground non-pressure drainage and sewerage networks - Part 1: General provisions

[13] PN-EN ISO 11296-4:2018-03 - Plastic piping systems for the renovation of underground non-pressure drainage and sewerage networks - Part 4: Lining with cured-in-place pipes

[14] PN-EN ISO 11297-1:2018-05 - Plastic piping systems for the renovation of underground drainage and sewerage networks under pressure - Part 1: General provisions

[15] PN-EN ISO 11297-4:2018-03 - Plastic piping systems for the renovation of underground drainage and sewerage networks under pressure - Part 4: Lining with cured-in-place pipes

[16] Kolonko A., 2003. Polish experience in the renovation of sewer pipes using CIPP sleeves, Inżynieria Bezwykopowa - August, Krakow.

[17] PN-EN ISO 14125:2001 - Fibre-reinforced plastic composites Determination of flexural properties

[18] PN-EN ISO 178:2019-06 - Plastics - Determination of flexural properties

[19] CIPP Liner Test Standard, IKT - Institute for Underground Infrastructure, Gelsenkirchen, 2009
[20] Allouche E. N., Bainbridge K., Moore I.D., 2005. Laboratory examination of a cured in place pressure pipe liner for a potable water distribution system, North American Society for Trenchless Technology (NASTT) NO-DIG 2005, Orlando.

[21] ASTM D790-17 Standard Test Methods for Flexural Properties of Unreinforced and Reinforced Plastics and Electrical Insulating Materials

[22] ASTM D638 - 14 Standard Test Method for Tensile Properties of Plastics

[23] Allouche E., Alam S., Simicevic J., Sterling R., Condit W., Matthews J., Selvakumar A., 2014. A pilot study for retrospective evaluation of cured-in-place pipe (CIPP) rehabilitation of municipal gravity sewers, Tunnelling and Underground Space Technology 39, 82-93.

[24] Abel T., 2015. Laboratory tests of pipelines reinforced with close-fit Trolining liner, Archives of Civil and Mechanical Engineering 15, $427-435$.

[25] Kuliczkowski A., Mogielski K. Results of laboratory tests of concrete, vitrified clay and pvc sewer pipes with CIPP liners, Environment 23-34.

[26] Ra K., Teimouri Sendesi S.M., Nuruddin Md., Zyakyina N.N., Conkling E.N., Boor B.E., Jafvert Ch.T., Howarter J.A., Youngblood J.P., Whelton A.J., 2019. Considerations for emission monitoring and liner analysis of thermally manufactured sewer cured-in-place-pipes (CIPP), Journal of Hazardous Materials, 371, 540-549.

[27] Abel T., 2016. Changes in strength parameters of pipelines rehabilitated with close-fit Trolining liners - Numerical analysis based on laboratory tests, Archives of Civil and Mechanical Engineering 16, 30 - 40.

[28] Calibration Certificate, 2012. Universal Testing Machine model WDW-100, China.

[29] PN-EN ISO 3126:2006 Plastic piping systems - Plastic components - Checking dimensions

[30] GWT manual, 2000. Germann Instruments, Denmark.

[31] Glock, D., 1977. Überkritisches Verhalten eines starr ummantelten Kreisrohres bei Wasserdruck von außen und Temperaturerhöhung, Der Stahlbau 46. 